University of Nebraska - Lincoln

DigitalCommons@University of Nebraska - Lincoln

USDA National Wildlife Research Center - Staff Publications
U.S. Department of Agriculture: Animal and Plant Health Inspection Service

2017

\title{
Study design concepts for inferring functional roles of mammalian top predators
}

Richard M. Engeman

USDA-APHIS-Wildlife Services, s_r100@yahoo.com

Lee R. Allen

Robert Wicks Pest Animal Research Centre, lee.allen@daf.qld.gov.au

Benjamin L. Allen

University of Southern Queensland, benjamin.allen@usq.edu.au

Follow this and additional works at: https://digitalcommons.unl.edu/icwdm_usdanwrc

Part of the Life Sciences Commons

Engeman, Richard M.; Allen, Lee R.; and Allen, Benjamin L., "Study design concepts for inferring functional roles of mammalian top predators" (2017). USDA National Wildlife Research Center - Staff Publications. 1985.

https://digitalcommons.unl.edu/icwdm_usdanwrc/1985

This Article is brought to you for free and open access by the U.S. Department of Agriculture: Animal and Plant Health Inspection Service at DigitalCommons@University of Nebraska - Lincoln. It has been accepted for inclusion in USDA National Wildlife Research Center - Staff Publications by an authorized administrator of DigitalCommons@University of Nebraska - Lincoln. 


\title{
Study design concepts for inferring functional roles of mammalian top predators
}

\author{
Richard M. Engeman ${ }^{\mathrm{a}, *}$, Lee R. Allen ${ }^{\mathrm{b}}$, Benjamin L. Allen ${ }^{\mathrm{c}}$ \\ ${ }^{a}$ National Wildlife Research Centre, 4101 LaPorte Avenue, Fort Collins, CO 80521-2154, USA \\ b Biosecurity Queensland, Robert Wicks Pest Animal Research Centre, 203 Tor Street, Toowoomba, Queensland 4350, Australia \\ c University of Southern Queensland, Institute for Agriculture and the Environment, West Street, Toowoomba, Queensland 4350, Australia
}

\section{A R T I C L E I N F O}

\section{Article history:}

Received 21 August 2015

Received in revised form 24 February 2017

Accepted 25 February 2017

Available online 28 February 2017

\section{Keywords:}

Confounding

Experimental design

Large carnivore

Mesopredator release

Population monitoring

Trophic cascade

\begin{abstract}
A B S T R A C T
The roles and functions of top predators have in recent years been an important yet controversial field of biodiversity conservation research. Interrelationships between sympatric species within complex systems can pose enormous challenges for designing studies that gain clear understanding of specific relationships and processes. Teasing out the nature of the relationships is made far more difficult, if not impossible, if the experimental design of the studies is flawed or too limited for the desired inferences, and/or if the observational methods are inappropriate or too unwieldy to obtain the necessary data validly. The most powerful observation methods for understanding the interrelationships among sympatric species require standardized and repeated observations of populations over time, seasons, habitats and geographic space. Yet, the most powerful experimental designs underpinning the observation methods actually rest in fairly straight-forward design concepts. The two general components for collecting such data are the design structure for the study (possible population manipulation, and where and when observations are to be made) and the procedures for making observations (population assessments) in each location at each time. Here, we discuss these and other experimental design concepts which, if followed, will assist in clarifying the ecological roles of top predators and resolving debates about these roles.
\end{abstract}

Published by Elsevier Inc

\section{Contents}

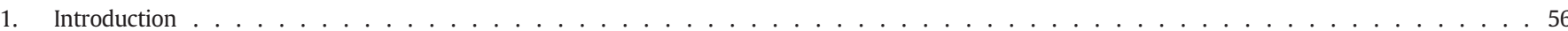

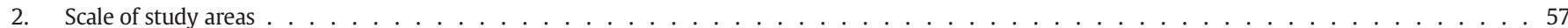

3. Features of classical experiments . . . . . . . . . . . . . . . . . . . . . . . . . . . . . . . . . . . . . . . . . . . . . . . . . . . . . 58

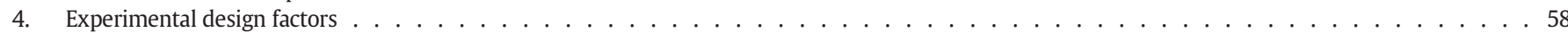

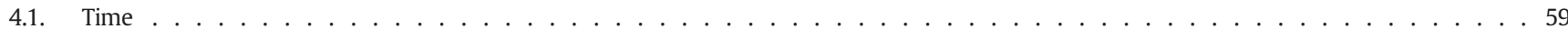

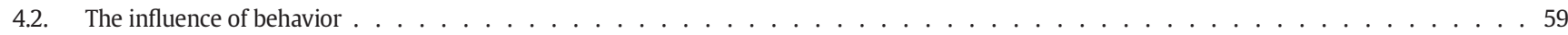

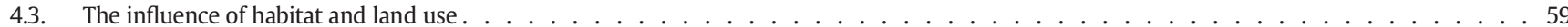

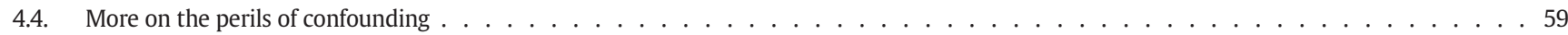

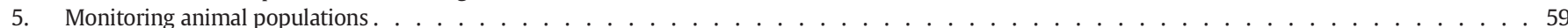

5.1. Where to make observations within an area . . . . . . . . . . . . . . . . . . . . . . . . . . . . . . . . 60

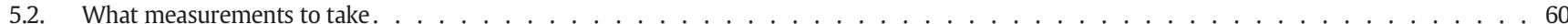

5.3. Assessment of interspecific relationships . . . . . . . . . . . . . . . . . . . . . . . . . 61

5.4. Sampling period for making observations at each sampling occasion. . . . . . . . . . . . . . . . . . . . . . . . . . . 61

6. Conclusion . . . . . . . . . . . . . . . . . . . . . . . . . . . . . . . . . . 61

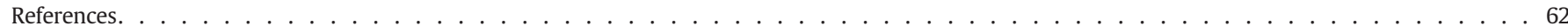

\footnotetext{
* Corresponding author.

E-mail addresses: Richard.M.Engeman@aphis.usda.gov (R.M. Engeman), Lee.Allen@daf.qld.gov.au (L.R. Allen), benjamin.allen@usq.edu.au (B.L. Allen).
}

\section{Introduction}

Exploring the roles and functions of large carnivores has been a prominent field of biodiversity conservation research in the last 10 
15 years (Estes et al., 2011; Ripple et al., 2014). Various studies have reported that large carnivores can indirectly alleviate predation on smaller (and often threatened) fauna and promote vegetation growth by interacting strongly (often negatively) with sympatric carnivore and herbivore species (Ray et al., 2005; Terborgh and Estes, 2010). It follows, then, that the local extinction of large carnivores and other top predators can be detrimental to biodiversity, and their subsequent reintroduction may produce positive biodiversity outcomes (Hayward and Somers, 2009; Ripple et al., 2014). However, despite (or perhaps because of) the simplicity of this concept and the wide array of literature on this issue, the function of top predators and their ability to generate these outcomes has attracted much debate and controversy (Smith et al., 2016; Allen et al., 2017).

Because food webs are so complex and dynamic, even examples receiving intensive study over many years present challenges for interpretation (Orians et al., 1997; Smith et al., 2016). When the studies used to assess trophic relationships are flawed in design or have weak inferential ability, the interpretations about predators' roles within the system and the effects human management actions might have on them is perilous at best, and rightly contested. Achieving consensus is important, because the fates of many large predators are depending on the resolution of these debates, made possible only through improved scientific rigor (Allen et al., 2017).

Sufficient reliable evidence suitable for use in evidence-based management of top predators is presently lacking for almost all top predators (Ripple et al., 2014; Allen et al., 2017). Moreover, studies on the roles and functions of top predators continue to struggle to implement study designs having the potential to generate the necessary reliable evidence (Allen et al., 2013b; MacNulty et al., 2016). We describe here concepts and key principles of sound study design and observation methods that are both rigorous and practical for investigating the potential roles of predators in causing trophic cascades. Many general descriptions of high-inference experimental design are already available in textbooks (e.g. Kershaw, 1969; Caughley and Sinclair, 1994; Zar, 1999; Fairweather and Quinn, 2006; Hone, 2007; Krebs, 2008). However, these can often be difficult to access and understand for many wildlife managers and researchers collecting the empirical data that will someday be used to investigate the six key relationships often discussed regarding on trophic cascades (Fig. 1). If researchers are to unravel the complexities of top predators' ecological roles in a dynamic environment, then the strength of the research needs to permit making inferences with confidence in their validity. Otherwise, decision-makers and land managers will struggle to make sense of incomplete or flawed information in developing management actions and practices (Allen et al., 2011b, 2013b).

Studies to obtain a sound understanding about the interrelationships among top predators and sympatric species require a breadth of observations over time, seasons, habitat types and geographic space. The scale for study needed to identify relationships may often appear daunting, yet the design concepts for structuring and carrying out observations from which data analyses can produce valid inferences actually rest in fairly straightforward statistical experimental design concepts. A complicating element is that inferences about the relationships among sympatric species require that multiple species are monitored simultaneously across the geographic and temporal breadth of the study. Hence, the scope of the study, coupled with simultaneous monitoring of multiple species, requires the methods to not only be capable of producing quantitatively valid inferences, but that they must also be practical to apply in the field. Accordingly, the two general components for collecting such data are the design structure for the study (possible population manipulation, and where and when observations are to be made) and the procedures for making observations (population assessments) in each location at each time. Each of these two components is addressed in the following sections, followed by a brief conclusion. We do not attempt to discuss methods of data analyses in the context of this review. Once quality data are collected the opportunity will exist to correctly analyze them statistically, but if flawed design or weak observational methods are used to collect the data, then there may be no analyses that can salvage valid information from the study.

\section{Scale of study areas}

Animal populations are not usually distributed uniformly across the landscape but are instead clumped, producing areas of higher and lower abundance (Krebs, 2008). The extent of population clumping often can be influenced by a range of factors, including habitat, season and/or resource availability. Thus, studies at small spatial scales relative to the home range sizes of the studied predator/s may produce severely biased results.

Selecting the appropriate spatial scale should depend on the type of inferences desired from the work. For example, if researchers want to make inferences about the effects of mesopredators on their prey species ( $R 3$ in Fig. 1), then the minimum size of the study area need only encompass a population of mesopredators and their prey. However, if researchers want to make inferences about the potential cascading effects of broad-scale top predator control on top predators, mesopredators and/or their prey species (R1, R4 and R6 in Fig. 1), then the scale of the study should be no less than the scale that top predator control is typically applied. In the cases of dingoes and grey wolves (Canis lupus), this usually requires areas tens of thousands of square kilometers in size (e.g. Eldridge et al., 2002; Hayes et al., 2003; Allen et al., 2014; Hervieux et al., 2014). Spatial scale has been shown to influence the effects observed (i.e. there is an inverse relationship between scale and the likelihood of detecting negative relationships between sympatric predators; e.g. Swanson et al., 2014; Allen et al., 2015). This means that authors must be diligent to not extend their conclusions beyond the limitations of their data when interpreting and communicating their results, and readers must be vigilant in looking for scale issues when evaluating the reliability and applicability of a given study.

Animal activity is also rarely distributed uniformly over temporal scales. Within a 24-h or daily period, animals may exhibit diurnal, nocturnal or crepuscular behavioral cycles which prevent reliable
R5

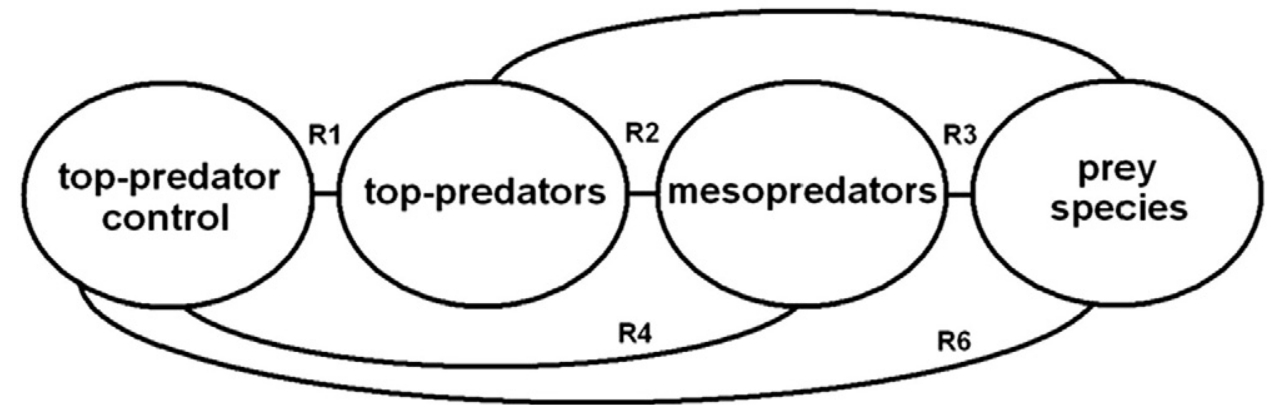

Fig. 1. - Schematic representation of the six primary interrelationships between prey species and top predator control by humans (from Allen et al., 2012). 
comparisons from one time to another. This may be most easily understood using birds as an example, where observations collected from one area in the early morning should not be compared to observations collected from another area at noon (Buckland et al., 2001; Johnson, 2008). Temporal variation in animal activity has also been observed over monthly cycles, often related to lunar effects (e.g. Spence-Bailey et al., 2010; Cozzi et al., 2012; Prugh and Golden, 2014). Where animals exhibit this variation, observations collected from one area at the new moon should not be compared with observations collected at another area during the full moon, for example. Temporal variation also exists over annual cycles, typically related to seasonal patterns affecting resource availability (e.g. snow cover, spring 'green up' etc.) and breeding cycles. As for daily and monthly variation, observations of animal activity at one area cannot be reliably compared and contrasted with observations from another area taken in different seasons (see below). These are because the influences of area and time period will almost certainly confound observations of 'activity' or 'relative abundance' in unknown ways. The key points when considering spatial and temporal scale is making sure that the scale of the study has the capacity to address the desired inferences, and that scales are taken into account when making inferences.

\section{Features of classical experiments}

The use of nil-treatments or experimental control sites is an indispensable component of studies desiring to make inferences about cause (e.g. top predator removal) and effect (e.g. mesopredator release). The replication and randomization of treatments are additional, particularly important design features that can greatly enhance the ability of an experiment to demonstrate causal processes. A key design ingredient for discerning causal relationships among top predators and their sympatric species applies to the concept of comparing areas receiving a treatment (or different levels of treatment) with those not receiving a treatment. Besides the application of treatment(s), the areas should be as similar as possible so that any differences discovered are most likely due to the treatment and not some other background effect (e.g. land use history). The purpose of sampling matched pairs (or more members in a 'block' of members if different levels of treatment are studied) is to control all factors except for the treatment effect of interest. Matching violations, such as paired sub-sites (pair members) containing different habitats and/or historical and contemporary land uses etc., result in confounded inferences. Studies on a broad geographic scale should incorporate the concept of matching untreated and treated areas within the various habitats and regions covered by the study.

The most authoritative conclusions about the influences of top predators are obtained if populations of those predators can be, or have been, manipulated (either as part of study protocol or existing management circumstances). There are two general approaches for treatment application when considering designs that incorporate untreated and treated pairs. One is to locate sets of matched pairs where one pair member can have a treatment applied, most likely as a management action (e.g. augmentation or removal of predators). The other is the case of already existing circumstances, where the investigator does not have as much control over the level and consistency of the treatment application as compared to circumstances where the treatment application was formally incorporated into a planned study protocol. This second, opportunistic approach of examining existing circumstances often is the most practical or only feasible approach available, but therefore requires caution in assuring a consistent meaning for 'treatment' and the confirmation of an actual treatment effect. Ideally, a study would incorporate a BACI (before-after, control-impact) design, with replicated treatments and controls, at scales large enough to permit the occurrence and concomitant detection of animal population changes (Glen et al., 2007).

There are two general forms of direct population manipulation of top predators: increase (to augment, introduce or relax control of) the population (e.g. wolf introduction to Yellowstone; Bangs and Smith,
2008) or reduce the population size (e.g. dingo control in Australia; Allen et al., 2013a, 2014). Both approaches can pose regulatory challenges in their implementation, and both approaches attract controversy. Whether removal or addition experiments are deemed best depends on the context. In general however, removal experiments may be most appropriate for dingoes given that they still occupy $85 \%$ of their former range, are naturally recovering in the remaining $15 \%$ of their range despite their lethal control there, and are therefore not of conservation concern (Allen and West, 2013). The opposite is true for wolves, which are absent from much of their former range, require assistance to recolonize these areas, and are of international conservation concern (Chapron et al., 2014).

Globally, many top predators are already subjected to control programs, so there exists potential to undertake removal experiments if comparable untreated areas can be identified for pairing. But simply stating that the predator population within a treated area has been subjected to manipulation (e.g. Letnic and Koch, 2010; Wallach et al., 2010; Colman et al., 2014) is grossly insufficient. Confirmation that the manipulation has actually affected the predator in some way (R1 in Fig. 1) is needed before inferences can be reliably made about any trophic effects of manipulation (R4 or R6 in Fig. 1; Allen et al., 2014). The intensity, scale and application of management actions can also be highly variable; 'predator control' in one area may not be same as 'predator control' in other areas, and cannot therefore be assumed to be the same treatment. For example, coyotes (Canis latrans) are controlled in many areas of the USA for livestock protection (Wagner and Conover, 1999; Berger, 2006). Some areas with regular livestock predation receive, often annual, preventative control in advance of lambing/calving, while other areas receive reactive control as a response when predation events take place. Such different control strategies would not be likely to have the same effect on coyotes, and therefore the same cascading effects (if any) on coyote's ecological roles within food webs.

To preclude or minimize a predator treatment on one study site (or paired sub-site) from influencing (biasing) the results on other site(s) in the study, a buffer zone should ideally separate the study sites. Because of the subtle habitat differences that can occur in landscapes that appear similar, a trade-off is likely to exist between treatment independence and treatment similarity when deciding on an appropriate buffer width, especially for large-scale studies. For instance, independence may increase and habitat similarity decrease the further apart two treatments are, and vice versa. It is important not to compare 'apples with oranges', so foundational data should be collected to verify within-pair site similarities, such as rainfall, vegetation types and other such information. This can then be used to identify population responses to variables besides the treatment, and therefore provide greater capacity to identify responses to the treatment. Replication of paired treated and untreated sites helps resolve these issues, especially in the face of background variability.

\section{Experimental design factors}

When attempting to design studies for identifying influences top predators have on sympatric species (R2 and R5 in Fig. 1), a number of design factors have to be taken into consideration. Not accounting for these factors in the study design can lead to false or misleading inferences due to confounding or bias. Unfortunately, many studies examining the impacts of predators have failed to fully account for these important factors (reviewed for wolves in Mech, 2012, and for dingoes in Allen et al., 2013b), resulting in inferences of questionable quality and possibly leading to accepted beliefs about and management of predators which are not supported by robust empirical data (e.g. Allen et al., 2017). Although accounting for existing factors leads to strengthened inferences about predator influences, those inferences will likely be correlative in nature unless a 'treatment' is included as a design factor where the top predator population is manipulated (see above). For example, if a variety of study areas across geographic space are 
appropriately sampled through time and show a negative correlation, say, between wolf and coyote abundances (e.g. Newsome and Ripple, 2015) or dingo and red fox (Vulpes vulpes) abundances (e.g. Letnic et al., 2011), the primary inferential temptation is to presume it is the abundance of the top predator causing the effect, when in fact it could well result from an associated unmeasured variable. Also, for such correlative data, it may be just as appropriate to say that the abundance of mesopredators causes the effect (Allen et al., 2012). Where studies use more observational methods, the results should be interpreted and valued as such, and not as equivalent to the results of classical experiments (Hone, 2007; but see also Platt, 1964; McArdle, 1996). Manipulative experiments typically trump correlative studies (Fleming et al., 2013).

Whether or not manipulation of top predator populations is possible, there are design issues to take into consideration to help assure maximal value from both manipulation and correlative studies. We next consider the incorporation of important factors into the study design so as to minimize the potential for confounding or bias, and we consider the consequences of false inferences if such factors are ignored in the design.

\subsection{Time}

Even with a well thought-out experimental design, observations at a single snapshot in time only indicate a current status and cannot provide information about system dynamics and processes. The dynamics of assessing interrelationships require accounting for the design factors while following each situation through time. Study duration should also be sufficient to differentiate between treatment effects and the expected stochastic variations typical across landscapes, such as rainfall and associated primary productivity (Glen et al., 2007). Results from snapshot or temporally restricted data cannot be used to make reliable inferences through time. To understand the dynamics of interspecies relationships over time requires observations through seasons within years and also observations in those seasons across years to see how relationships are influenced by different conditions, such as productive versus unproductive years.

\subsection{The influence of behavior}

Animal activity naturally fluctuates throughout the year in response to seasonal patterns and significant, yet normal changes often occur over just a few weeks (as above). Thus, regardless of a treatment, valid comparisons cannot be made between one site sampled in winter and another site sampled in summer, because observed differences are likely to be attributable to behavioral changes or patterns and not abundance changes. The effect of season on species activity is most obvious for species that reduce their activity or hibernate during cooler months. This behavior reflects activity changes, not abundance changes, because animals do not die off each winter, they just become less active.

Top predators often exhibit seasonal activity changes related to periods of courtship, breeding, raising young, and dispersal. Interspecific avoidance behaviors also influence the detection of certain species at different times (e.g. Fancourt, 2016). For these reasons, comparisons of observations made from different daily, monthly or yearly timeframes cannot be accurately compared or pooled for analysis (Caughley, 1980; Engeman, 2005). This is because comparisons among different times/seasons would confound relative abundance differences with behavioral differences, whereas pooling across seasons would mask differences that could be more appropriately identified within a season (Allen et al., 2011a). When attempting to document numerical responses of mesopredators to changes in top predator abundances (R2 in Fig. 1), the appropriate timeframe should at least be greater than one breeding cycle of all predators involved (often one year), because observed short-term responses may not translate into long-term numerical responses due to compensatory breeding and other effects.

\subsection{The influence of habitat and land use}

Habitat or land use may also influence species activity, implying that comparisons between different habitats are a ready source for confounding due to varying detection probabilities associated with different habitat types (Engeman, 2005; MacKenzie et al., 2006). For instance, 'open' habitats (such as sandy deserts or grasslands) may afford a more even distribution of activity across the landscape because there are few physical barriers to movement patterns, whereas 'closed' habitats (such as rocky ranges, or dense forest) may direct movements on to travel pathways such as trails, tracks, and roads. Land use patterns are known to influence occupancy or abundance patterns of whole predator communities, where abundances of a given predator are strongly influenced by land use or habitat type and not necessarily the presence or absence of predators at higher trophic levels (e.g. Schuette et al., 2013; Pasanen-Mortensen and Elmhagen, 2015). Availability and proximity of refugia may also influence the activity of smaller prey species. Other, more subtle differences affecting smaller prey species may occur between land uses within a similar overall habitat, such as the size of the seed bank available to granivorous species. Different habitats also usually have different faunal assemblages, geological and ecological processes, which may influence the ability to observe animals. Similar to the potential confounding influence of time or behavior, ignoring habitat or land use can also render intended comparisons invalid and unreliable.

\subsection{More on the perils of confounding}

Multicausality is a form of confounding where there can be more than one plausible explanation for the observation or result. Our emphasis on the influence of time, behavior and habitat is essentially a plea to remove these common factors from the list of potential factors likely to explain the results described in many studies of predators' roles. Improving and accounting for these design issues can eliminate their confounding influence and focus attention on the harder-to-address issues, like scale or climatic conditions. Should studies be designed with treatments and controls, with replication and randomization where possible, and then use properly paired sites with standardized observation procedures that account for the influence of time, behavior and habitat, then researchers can narrow-in on the true causes for observed cascading changes associated with top predators while avoiding the common pitfalls presently systemic in the literature.

\section{Monitoring animal populations}

We have already considered design factors for structuring a study and how study areas are incorporated within it. Now we consider how to monitor sympatric wildlife species within an area, recognizing that such an 'area' is likely to be an individual sampling unit among others in a larger study design where the same observation protocol will be carried out.

Wilson and Delahay (2001) and Engeman (2005) have outlined a widely applicable framework for sampling animal populations using common observation methods, such as tracking plots, camera traps, spotlighting, chew cards and other means. They describe the principles and analytical methods governing their proper use for making reliable inferences about species abundance. The principles described in these reports are simple reflections of elementary statistical sampling and design. Hence, studies not accounting for them may offer unreliable evidence due to biased data or confounded inferences.

With a multi-site and multi-year study, appropriate techniques for population monitoring of top predators, predators and potential prey species are required in order to obtain adequate data on the relative dynamics of the interrelationships. Free-ranging animals are typically difficult to survey, especially predators. This is because many predators expressly try to avoid detection, often occur in relatively low numbers 
in the landscape, and/or occupy terrain and habitat that make them difficult to observe. Various methods of surveying presence/absence, abundance or density are used to assess free-ranging species (e.g. Pollock, 1995; Sutherland, 1996), with the method chosen being a function of the objectives of the study, the resources available, and the size, abundance and behavior of the target species. We note, however, that accurate knowledge of absolute abundance is near impossible to acquire in the field. Issues of immigration, emigration, births, deaths, various forms of heterogeneity in catchability, loss of identification marks and detection all frustrate valid estimation of absolute numbers of animals. Modern methods to overcome these obstacles often require more data than is feasible or possible to obtain (Caughley, 1980). However, strict application of certain principles can produce reliable estimates of relative abundance. Direct enumeration or density estimates are often not required or possible for large-scale studies simultaneously involving multiple species. Therefore, indirect counts or indices of relative abundance are frequently employed to monitor population trends, responses to management actions, or relationships between species (e.g. Beier and Cunningham, 1996; Blaum et al., 2008; Johnson, 2008; Evangelista et al., 2009; Sobrino et al., 2009; Bengsen et al., 2011a, 2011b; Allen et al., 2014; Güthlin et al., 2014; Kojola et al., 2014).

An index is a statistic related to the variable in question (Caughley, 1980; Sutherland, 1996; Krebs, 2008) and specific to the circumstances under which the data were collected (Engeman, 2005). The greatest value of such indirect relative abundance measures is in monitoring population trends at the same location or from similar locations at the same time. Metrics of population size are maximally informative when placed in context with comparative values to assess trends, changes or differences. The primary driving force for applying indexing procedures is that they can be robust, practical or feasible methods for simultaneous monitoring of multiple animal populations. Statistical theory has been developed for a broad class of indexing approaches (Caughley, 1980; Pollock et al., 2002; Engeman, 2005) and methods for estimating variance and validating indexing procedures have been developed (Engeman et al., 1998; Bengsen et al., 2011b; Allen and Engeman, 2014). Strict application of such sampling techniques can produce a population sampling method that can reliably detect species at low levels of abundance, produce relative abundance values with minimal variance, and capably measure changes in abundance with minimal sampling effort and expertise.

\subsection{Where to make observations within an area}

We generically refer to the locations for making observations within an area as stations. For example, each station might be a sand plot for observing animal tracks, a camera location, bird survey point, or other observation type.

Animal abundance and activity typically are not randomly or uniformly distributed across the landscape (see above), thereby contributing to station-to-station variability (e.g., Engeman, 2005). Thus, it is also important to consider the overall number and spatial distribution of stations relative to the area for which inferences are being made. To monitor a population within an area, observation stations should be set throughout the survey area of interest. The distribution of observation stations must be carefully considered relative to efficiency in obtaining adequate measurements of the animals being monitored and avoiding bias in the results that could be induced by station placement. It is important to keep in mind that the objective is not to sample the geographical area, but rather the population inhabiting that area. Thus, station locations may take advantage of animal behavioral characteristics by placing stations where they would most likely intersect the usual activities of the target animals (Engeman et al., 2002). This is similar in concept to the capture of animals, where capture devices are not placed with complete randomness, but rather placed where an animal is most likely to encounter the capture device. While random or systematic (e.g. grid) placement of stations throughout a study area would be acceptable in theory, landscapes and animal behavior are often not consistent with theory. Random or systematic placement of observation stations can be useful placement strategies if landscapes are uniform and animals are equally likely to be anywhere in the area. However, in many circumstances, there are significant downsides to such approaches. True random or systematic station placements may set stations in physically impossible locations (e.g. cliff faces, under water etc.). Moreover, even in smooth or uniform terrain, locating random or systematically-placed stations may be more difficult than other strategies. If animal usage within the study area is predictable, then either random or systematic station placement strategies is likely to be inefficient for obtaining observations (more stations would be needed).

Examples of where stations can be placed to intercept animal activity include roads/tracks, game trails, river banks, sand lines (especially along beaches and dunes), a food or water resource, and many others. Consider a tracking plot example for collecting data. Many species preferentially use the path of least resistance for travel or delineation of territories, which often includes dirt roads or tracks as travel ways. If such travel ways are distributed throughout the area of interest (e.g. a plantation forest dissected with access roads), they can provide a means for station placement that is both efficient and representative for sampling of the population using the surrounding habitat.

Care and common sense must be applied when choosing to take advantage of these behavioral characteristics for monitoring animals. If roads or tracks are not dispersed through the area of interest, then observations only from them would be less likely to be representative of the population throughout the area. If multiple assessments are to be made through time on the same area, then the same station locations should also be used during each repeated survey. If the area of interest is comprised of different habitat types, then it is advisable to stratify station placement according to habitat type, thus helping to insure that the calculated index values reflect the population throughout the area rather than being overly biased towards (or away from) a particular subset of available habitats. Even methods well-established for a broad class of species should still be tested when applied to a new species, even if closely related, and especially if the method also had not been tested in its habitat (Evangelista et al., 2009).

\subsection{What measurements to take}

There is a wide array of potential methods for making observations suitable for monitoring multiple animal populations. In selecting an observation method or methods to apply at each station a variety of important questions should be asked of each method under consideration:

- Does the method satisfy the study objectives?

- Does the method allow sufficient sensitivity to population changes/ differences?

- Is the method practical compared to other approaches?

- Are the resulting data valid for the intended analyses and inferences?

- Is the method tested?

- How reliant is the method on analytical assumptions and are they likely to be fulfilled?

- Will the data collected allow multiple analytical approaches, or restrict the potential analytical approaches available?

Many types of measurements can fit the above observational structure, including the general categories of animal counts, measurements of animal sign, and catch per unit effort (e.g. via dung counts, camera traps etc.). Moreover, the observations taken at each station are most valuable if they offer a continuum of possible measurements, rather than being binary (i.e. presence-absence) measurements (e.g. Engeman, 2005; Allen et al., 2011a). The variety of non-binary indexing measurements at different types of observation stations can include, for example, the number of intrusions by each species of animal onto a dirt tracking plot, the number of photos of a species within a fixed time 
period, the proportion or amount of bait consumed, the number of individuals (of each species) observed in a (a priori defined) fixed amount of time within a fixed distance at each station, and so on. Often, potentially continuous measures have been neglected in favor of binary observations (i.e. presence-absence measures at each station) due to a belief that binary observations are 'more conservative'. But 'more conservative' is often akin to 'less sensitive'. Binary observations have often been made because a continuous measurement was more difficult to make or was not considered. For example, tracking plots are easier to record as showing activity or not, without accurately recording the intensity of activity at each station. Similarly, it is easier to note that there is at least one photo of a particular species at a camera station than reviewing all photos and counting of the number of times the species was photographed. But reduction of potentially continuous data to binary observations is very easily demonstrated to have less descriptive ability and result in a greater opportunity for erroneous inferences (Engeman et al., 2000; Allen et al., 2011a).

Regardless of the type of measurement taken, the construction of stations should be consistent. This applies to the dimensions (size and shape) of the stations, as well as to time, weight or any other characteristic of the stations. For example, bait-take stations should each start with the same amount of bait and be observed for the same amount of time (with more bait supplied than is likely to be consumed in the observation period). Note that if baits or lures are used to attract animals to stations, then the same baits or lures must be used throughout the study, otherwise 'lure type' can be unnecessarily introduced as a potential confounding factor. Population indices (say, with cameras or tracks) derived by attracting animals to one bait type are not comparable to those derived using a different bait type. Stations for animal counts should also be observed for the same length of time and within the same distance limit. For example, camera stations should have consistent estimated focal ranges (the area in the camera's view), the same equipment capabilities and settings (such as for minimal time between photos) and with sufficient battery life and memory capacity to obtain and store all potential photographic opportunities (Meek et al., 2012, 2014).

An animal 'visit' to a station is not always a straightforward observation. To insure consistency among observations, what constitutes a 'visit' should also be defined a priori. For instance, using camera traps as an example, the time set to elapse between successive photos can define individual visits to the station. If individuals are uniquely distinguishable (e.g. by size, sex and coat color), then the number of individuals may be the measure of interest. For tracking plot observations, the number of intrusions by a species into a tracking plot is commonly used to monitor many wildlife species.

\subsection{Assessment of interspecific relationships}

Methods such as cameras and tracking plots allow simultaneous monitoring of multiple species. However, although the data may be collected at the same times in the same places, it is not appropriate to compare and contrast index values from different species. Trends over time and correlations can be used to look for relationships between species, but the magnitudes of values cannot be compared or contrasted between species. For example, consider relative abundance index values of 10 wolf tracks per kilometer and 5 coyote tracks per kilometer collected properly at the same site and time; although it is tempting, one cannot validly infer that coyotes are half as abundant as wolves. This is because a variety of factors (e.g. movement patterns, fine-scale spatial avoidance) may be responsible for the observed index values independent of abundance. Even though magnitudes of index values are not appropriate for comparison between species, the population trends defined by the index values over time can be valid given appropriate study design and data analyses (Engeman, 2005). When surveys are repeated over several seasons or years, resulting trends may be reliably used to identify relationships between predators. As an example, consider dingoes' influence on mesopredators in Australia using tracking plots to obtain observations (e.g. Allen et al., 2013a, 2014). Mesopredator activity on tracking plots may be much lower than those of dingoes for any (or every) given survey, but when surveyed repeatedly over longer timeframes, correlations between dingo and mesopredator population trends can be confidently compared. When dingo abundance is further manipulated in an experimental framework, a divergence of trends between dingoes and mesopredator would be particularly strong evidence for mesopredator release. The corollary of this is that non-divergence of dingo and mesopredator population trends over time would be particularly strong evidence that mesopredator suppression by dingoes is not occurring, which was the case in these large-scale manipulative experiments (Allen et al., 2013a, 2014).

\subsection{Sampling period for making observations at each sampling occasion}

Because animal activity is often variable over even very short time frames (see above), the stations are best observed on more than one occasion during an assessment period or survey. Typically, this means taking measurements at each station on multiple consecutive days, but for some applications this could mean taking measurements at other regular times, such as every other day. The time dimension is often referred to as a day effect, representing a common situation where observations at each indexing session would be made on multiple, usually consecutive, days. The time elapsed between successive observations at each station should remain constant. For example, assume observations are to be made at three time points. The time lapsed for accumulation of data should be constant at each of the three observation times. If tracking plots are to be observed $24 \mathrm{~h}$ after plot preparation, then each successive observation of the plots should also be made $24 \mathrm{~h}$ after plot preparation.

\section{Conclusion}

Top predators are difficult to study under even perfect conditions, let alone the imperfect or complex conditions that prevail in nature. Obtaining meaningful data from studies is made even more difficult if invalid, poor quality or low-inference experimental designs and population sampling methods are used. Should this be the case, data analyses often becomes a disappointing 'salvage job' attempting to extract some piece of reliable information from the study. This scenario can be avoided through implementation of rigorous experimental designs and population sampling procedures. Assessing top predator relationships with sympatric species adds to the complexity for producing valid inferences. We have attempted to broadly cover some important and readily applicable concepts to consider when aiming to study relationships between top predators and sympatric species. The information covered is generally useful, but is not intended to discount other useful approaches for designing studies and making observations. Nevertheless, the design concepts described for avoiding the common pitfalls of confounding are quite universal in application.

Although much of what is presented here has already been described in much more detail in many other sources, it can be astonishing just how frequently such concepts are neglected in the literature on top predators' roles in trophic cascades (Allen et al., 2017). Perfect experimental designs may be executed imperfectly, while imperfect designs may be executed perfectly. But neither promote reliable inference. As White (2001; pg. 383) cautioned, "don't even start the project if you can't do it right." Our hope is that the general information here may be used by those considering future study of top predators to 'do it right', both to avoid unnecessary debates and improve the quality of evidence-based top predator management. 


\section{References}

Allen, L.R., Engeman, R.M., 2014. Evaluating and validating abundance monitoring methods in the absence of populations of known size: review and application to a passive tracking index. Environ. Sci. Pollut. Res. 22, 2907-2915.

Allen, B.L., West, P., 2013. The influence of dingoes on sheep distribution in Australia. Aust. Vet. J. 91, 261-267.

Allen, B.L., Engeman, R.M., Allen, L.R., 2011a. Wild dogma I: an examination of recent "evidence" for dingo regulation of invasive mesopredator release in Australia. Curr. Zool. 57 (5), 568-583.

Allen, B.L., Engeman, R.M., Allen, L.R., 2011b. Wild dogma II: the role and implications of wild dogma for wild dog management in Australia. Curr. Zool. 57 (6), 737-740.

Allen, B.L., Fleming, P.J.S., Hayward, M., Allen, L.R., Engeman, R.M., Ballard, G., Leung, L.K.P., 2012. Top-predators as biodiversity regulators: contemporary issues affecting knowledge and management of dingoes in Australia. In: Lameed, G.A. (Ed.), Biodiversity Enrichment in a Diverse World. InTech Publishing, Rijeka, Croatia, pp. 85-132 (Chapter 4).

Allen, B.L., Allen, L.R., Engeman, R.M., Leung, L.K.-P., 2013a. Intraguild relationships between sympatric predators exposed to lethal control: predator manipulation experiments. Front. Zool. 10, 39.

Allen, B.L., Fleming, P.J.S., Allen, L.R., Engeman, R.M., Ballard, G., Leung, L.K.-P., 2013b. As clear as mud: a critical review of evidence for the ecological roles of Australian dingoes. Biol. Conserv. 159, 158-174.

Allen, B.L., Allen, L.R., Engeman, R.M., Leung, L.K.-P., 2014. Sympatric prey responses to lethal top-predator control: predator manipulation experiments. Front. Zool. 11, 56.

Allen, B.L., Allen, L.R., Leung, K.-P., 2015. Interactions between two naturalised invasive predators in Australia: are feral cats suppressed by dingoes? Biol. Invasions 17, 761-776.

Allen, B.L., Allen, L.R., Andrén, H., Ballard, G., Boitani, L., Engeman, R.M., Fleming, P.J.S., Haswell, P.M., Kowalczyk, R., Linnell, J.D.C., Mech, L.D., Parker, D.M., 2017. Can we save large carnivores without losing large carnivore science? Food Webs 12, 63-74.

Bangs, E.E., Smith, D.W., 2008. Re-introduction of the gray wolf into Yellowstone National Park and central Idaho, USA. In: Soorae, P.S. (Ed.), Global Re-introduction Perspectives: Re-introduction case studies from around the globe. IUCN/SSC Re-introduction Specialist Group, Abu Dhabi, UAE, pp. 167-171.

Beier, P., Cunningham, S.C., 1996. Power of track counts to detect changes in cougar populations. Wildl. Soc. Bull. 24, 540-546.

Bengsen, A.J., Butler, J., Masters, P., 2011a. Estimating and indexing feral cat population abundances using camera traps. Wildl. Res. 38 (8), 732-739.

Bengsen, A.J., Leung, L.K.P., Lapidge, S.J., Gordon, I.J., 2011b. Using a general index approach to analyze camera-trap abundance indices. J. Wildl. Manag. 75 (5), $1222-1227$.

Berger, K.M., 2006. Carnivore-livestock conflicts: effects of subsidized predator control and economic correlates on the sheep industry. Conserv. Biol. 20 (3), 751-761.

Blaum, N., Engeman, R.M., Wasiolka, B., Rossmanith, E., 2008. Indexing small mammalian carnivores in the southern Kalahari, South Africa. Wildl. Res. 35 (1), 72-79.

Buckland, S.T., Anderson, D.R., Burnham, K.P., Laake, J.L., Borchers, D.L., Thomas, L.N., 2001. Introduction to Distance Sampling: Estimating Abundance of Biological Populations. Oxford University Press, Oxford.

Caughley, G., 1980. Analysis of Vertebrate Populations (Reprinted with Corrections Edn). John Wiley \& Sons Ltd, Chichester.

Caughley, G., Sinclair, A.R.E., 1994. Wildlife Ecology and Management. Blackwell Sciences, Cambridge, Massachusetts.

Chapron, G., Kaczensky, P., Linnell, J.D.C., von Arx, M., Huber, D., Andrén, H., LópezBao, J.V., Adamec, M., Álvares, F., Anders, O., Balčiauskas, L., Balys, V., Bedő, P., Bego, F., Blanco, J.C., Breitenmoser, U., Brøseth, H., Bufka, L., Bunikyte, R., Ciucci, P., Dutsov, A., Engleder, T., Fuxjäger, C., Groff, C., Holmala, K., Hoxha, B., Iliopoulos, Y., Ionescu, O., Jeremić, J., Jerina, K., Kluth, G., Knauer, F., Kojola, I., Kos, I., Krofel, M., Kubala, J., Kunovac, S., Kusak, J., Kutal, M., Liberg, O., Majić, A., Männil, P., Manz, R., Marboutin, E., Marucco, F., Melovski, D., Mersini, K., Mertzanis, Y., Mysłajek, R.W., Nowak, S., Odden, J., Ozolins, J., Palomero, G., Paunović, M., Persson, J., Potočnik, H., Quenette, P.-Y., Rauer, G., Reinhardt, I., Rigg, R., Ryser, A., Salvatori, V., Skrbinšek, T., Stojanov, A., Swenson, J.E., Szemethy, L., Trajçe, A., Tsingarska-Sedefcheva, E., Váňa, M., Veeroja, R., Wabakken, P., Wölfl, M., Wölfl, S., Zimmermann, F., Zlatanova, D., Boitani, L. 2014. Recovery of large carnivores in Europe's modern human-dominated landscapes. Science 346 (6216), 1517-1519.

Colman, N.J., Gordon, C.E., Crowther, M.S., Letnic, M., 2014. Lethal control of an apex predator has unintended cascading effects on forest mammal assemblages. Proc. R. Soc. B Biol. Sci. 281 (1782), 20133094.

Cozzi, G., Broekhuis, F., McNutt, J.W., Turnbull, L.A., Macdonald, D.W., Schmid, B., 2012. Fear of the dark or dinner by moonlight? Reduced temporal partitioning among Africa's large carnivores. Ecology 93 (12), 2590-2599.

Eldridge, S.R., Shakeshaft, B.J., Nano, T.J., 2002. The impact of wild dog control on cattle, native and introduced herbivores and introduced predators in central Australia. Final Report to the Bureau of Rural Sciences. Parks and Wildlife Commission of the Northern Territory, Alice Springs.

Engeman, R., 2005. Indexing principles and a widely applicable paradigm for indexing animal populations. Wildl. Res. 32 (3), 202-210.

Engeman, R.M., Allen, L.R., Zerbe, G.O., 1998. Variance estimate for the activity index of Allen et al. Wildl. Res. 25 (6), 643-648.

Engeman, R.M., Pipas, M.J., Gruver, K.S., Allen, L.R., 2000. Monitoring coyote population changes with a passive activity index. Wildl. Res. 27, 553-557.

Engeman, R., Pipas, M., Gruver, K., Bourassa, J., Allen, L., 2002. Plot placement when using a passive tracking index to simultaneously monitor multiple species of animals. Wildl. Res. 29 (1), 85-90.
Estes, J.A., Terborgh, J., Brashares, J.S., Power, M.E., Berger, J., Bond, W.J., Carpenter, S.R Essington, T.E., Holt, R.D., Jackson, J.B.C., Marquis, R.J., Oksanen, L., Oksanen, T., Paine, R.T., Pikitch, E.K., Ripple, W.J., Sandin, S.A., Scheffer, M., Schoener, T.W., Shurin, J.B., Sinclair, A.R.E., Soulé, M.E., Virtanen, R., Wardle, D.A., 2011. Trophic downgrading of planet earth. Science 333, 301-306.

Evangelista, P., Engeman, R., Tallents, L., 2009. Testing a passive tracking index for monitoring the endangered Ethiopian wolf. Integr. Zool. 4, 172-178.

Fairweather, P., Quinn, G., 2006. Design of sampling and experiments in ecology. In: Attiwill, P., Wilson, B. (Eds.), Ecology: An Australian Perspective. Oxford University Press, Melbourne.

Fancourt, B.A., 2016. Avoiding the subject: the implications of avoidance behaviour for detecting predators. Behav. Ecol. Sociobiol. 70 (9), 1535-1546.

Fleming, P.J.S., Allen, B.L., Ballard, G., 2013. Cautionary considerations for positive dingo management: a response to the Johnson and Ritchie critique of Fleming et al. (2012). Aust. Mammal. 35 (1), 15-22.

Glen, A.S., Dickman, C.R., Soulé, M.E., Mackey, B.G., 2007. Evaluating the role of the dingo as a trophic regulator in Australian ecosystems. Austral Ecol. 32 (5), 492-501.

Güthlin, D., Storch, I., Küchenhoff, H., 2014. Toward reliable estimates of abundance: comparing index methods to assess the abundance of a mammalian predator. PLoS One 9 (4), e94537.

Hayes, R.D., Farnell, R., Ward, R.M.P., Carey, J., Dehn, M., Kuzyk, G.W., Baer, A.M., Gardner, C.L., O'Donoghue, M., 2003. Experimental reduction of wolves in the Yukon: ungulate responses and management implications. Wildl. Monogr. 152, 1-35.

Hayward, M.W., Somers, M.J., 2009. Reintroduction of Top-order Predators. Wiley-Blackwell, Oxford.

Hervieux, D., Hebblewhite, M., Stepnisky, D., Bacon, M., Boutin, S., 2014. Managing wolves (Canis lupus) to recover threatened woodland caribou (Rangifer tarandus caribou) in Alberta. Can. J. Zool. 92 (12), 1029-1037.

Hone, J., 2007. Wildlife Damage Control. CSIRO Publishing, Collingwood, Victoria.

Johnson, D.H., 2008. In defense of indices: the case of bird surveys. J. Wildl. Manag. 72 (4), 857-868.

Kershaw, K.A., 1969. Quantitative and Dynamic Ecology. Edward Arnold Publishers, London.

Kojola, I., Helle, P., Heikkinen, S., Lindén, H., Paasivaara, A., Wikman, M., 2014. Tracks in snow and population size estimation: the wolf Canis lupus in Finland. Wildl. Biol. 20 (5), 279-284.

Krebs, C.J., 2008. Ecology: The Experimental Analysis of Distribution and Abundance. 6 ed. Benjamin-Cummings Publishing, San Francisco.

Letnic, M., Koch, F., 2010. Are dingoes a trophic regulator in arid Australia? A comparison of mammal communities on either side of the dingo fence. Austral Ecol. 35 (2) (267175).

Letnic, M., Greenville, A., Denny, E., Dickman, C.R., Tischler, M., Gordon, C., Koch, F., 2011 Does a top predator suppress the abundance of an invasive mesopredator at a continental scale? Glob. Ecol. Biogeogr. 20 (2), 343-353.

MacKenzie, D.I., Nichols, J.D., Royle, J.A., Pollock, K.H., Bailey, L.L., Hines, J.E., 2006. Occupancy Estimation and Modelling: Inferring Patterns and Dynamics of Species Occurrence. Academic Press (Elsevier), London.

MacNulty, D.R., Stahler, D.R., Wyman, C.T., Ruprecht, J., Smith, D.W., 2016. The challenge of understanding northern Yellowstone elk dynamics after wolf reintroduction. Yellowstone Sci. 24 (1), 25-33.

McArdle, B.H., 1996. Levels of evidence in studies of competition, predation, and disease. N. Z. J. Ecol. 20 (1), 7-15.

Mech, L.D., 2012. Is science in danger of sanctifying the wolf? Biol. Conserv. 150, 143-149.

Meek, P.D., Ballard, G., Fleming, P.J.S., 2012. An Introduction to Camera Trapping for Wildlife Surveys in Australia. PestSmart Toolkit Publication. Invasive Animals Cooperative Research Centre, Canberra, Australia.

Meek, P.D., Ballard, G., Claridge, A., Kays, R., Moseby, K., O'Brien, T., O'Connell, A., Sanderson, J., Swann, D.E., Tobler, M., Townsend, S., 2014. Recommended guiding principles for reporting on camera trapping research. Biodivers. Conserv. 23 (9), 2321-2343.

Newsome, T.M., Ripple, W.J., 2015. A continental scale trophic cascade from wolves through coyotes to foxes. J. Anim. Ecol. 84 (1), 49-59.

Orians, G.H., Cochran, P.A., Duffield, J.W., Fuller, T.K., Gutierrez, R.J., Haneman, W.M., James, F.C., Kareiva, P., Kellert, S.R., Klein, D., McLellan, B.N., Olson, P.D., Yaska, G., 1997. Wolves, Bears, and their Prey in Alaska: Biological and Social Challenges in Wildlife Management. National Research Council, Washington DC.

Pasanen-Mortensen, M., Elmhagen, B., 2015. Land cover effects on mesopredator abundance in the presence and absence of apex predators. Acta Oecol. 67 (0), 40-48.

Platt, J.R., 1964. Strong inference: certain systematic methods of scientific thinking may produce much more rapid progress than others. Science 146 (3642), 347-353.

Pollock, K.H., 1995. The challenge of measuring change in wildlife populations: biometrician's perspective. In: Grigg, G.C., Hale, P.T., Lunney, D. (Eds.), Conservation through the Sustainable Use of Wildlife. Centre for Conservation Biology: The University of Queensland, pp. 117-121.

Pollock, K.H., Nichols, J.D., Simons, T.R., Farnsworth, G.L., Bailey, L.L., Sauer, J.R., 2002. Large scale wildlife monitoring studies: statistical methods for design and analysis. Environmetrics 13 (2), 105-119.

Prugh, L.R., Golden, C.D., 2014. Does moonlight increase predation risk? Meta-analysis reveals divergent responses of nocturnal mammals to lunar cycles. J. Anim. Ecol. 83 (2), 504-514.

Ray, J.C., Redford, K.H., Steneck, R.S., Berger, J., 2005. Large Carnivores and the Conservation of Biodiversity. Island Press, Washington.

Ripple, W.J., Estes, J.A., Beschta, R.L., Wilmers, C.C., Ritchie, E.G., Hebblewhite, M., Berger, J. Elmhagen, B., Letnic, M., Nelson, M.P., Schmitz, O.J., Smith, D.W., Wallach, A.D., Wirsing, A.J., 2014. Status and ecological effects of the world's largest carnivores. Science 343, 151-163. 
Schuette, P., Wagner, A.P., Wagner, M.E., Creel, S., 2013. Occupancy patterns and niche partitioning within a diverse carnivore community exposed to anthropogenic pressures. Biol. Conserv. 158, 301-312.

Smith, D.W., Peterson, R.O., MacNulty, D.R., Kohl, M., 2016. The big scientific debate: trophic cascades. Yellowstone Sci. 24 (1), 70-71.

Sobrino, R., Acevedo, P., Escudero, M., Marco, J., Gortázar, C., 2009. Carnivore population trends in Spanish agrosystems after the reduction in food availability due to rabbit decline by rabbit haemorrhagic disease and improved waste management. Eur. J. Wildl. Res. 55 (2), 161-165.

Spence-Bailey, L.M., Nimmo, D.G., Kelly, L.T., Bennett, A.F., Clarke, M.F., 2010. Maximising trapping efficiency in reptile surveys: the role of seasonality, weather conditions and moon phase on capture success. Wildl. Res. 37 (2), 104-115.

Sutherland, W.J., 1996. Ecological Census Techniques. Cambridge University Press, Cambridge, UK.
Swanson, A., Caro, T., Davies-Mostert, H.T., Mills, M.G.L., Macdonald, D.W., Borner, M., Masenga, E., Packer, C., 2014. Cheetahs and wild dogs show contrasting patterns of suppression by lions. J. Anim. Ecol. 83 (6), 1418-1427.

Terborgh, J., Estes, J.A., 2010. Trophic Cascades: Predator, Prey, and the Changing Dynamics of Nature. Island Press, Washington D.C.

Wagner, K.K., Conover, M.R., 1999. Effect of preventive coyote hunting on sheep losses to coyote predation. J. Wildl. Manag. 63 (2), 606-612.

Wallach, A.D., Johnson, C.N., Ritchie, E.G., O'Neill, A.J., 2010. Predator control promotes invasive dominated ecological states. Ecol. Lett. 13, 1008-1018.

White, G.C., 2001. Why take calculus? Rigour in wildlife management. Wildl. Soc. Bull. 29, 380-386.

Wilson, G.J., Delahay, R.J., 2001. A review of methods to estimate the abundance of terrestrial carnivores using field signs and observation. Wildl. Res. 28, 151-164.

Zar, J.H., 1999. Biostatistical Analysis. 4 ed. Prentice-Hall, New Jersey. 